\title{
Sleep and circadian rhythm in response to the COVID-19 pandemic
}

\author{
Charles M. Morin ${ }^{1,2}$ (D) Julie Carrier ${ }^{3,4} \cdot$ Célyne Bastien $^{1,2} \cdot$ Roger Godbout ${ }^{3,5} \cdot$ On behalf of the Canadian Sleep and \\ Circadian Network
}

Received: 1 June 2020 / Accepted: 1 July 2020 / Published online: 22 July 2020

(C) The Canadian Public Health Association 2020

\begin{abstract}
This commentary highlights the critical role of sleep as a public health issue, particularly during a stressful life period such as the COVID-19 pandemic, and provides evidence-based practical guidelines to manage sleep disturbances during this crisis. The COVID19 pandemic and the imposed social confinement have produced significant stress, anxiety, and worries about health and the fear of being infected, jobs and financial problems, and uncertainty about the future. The incidence of sleep disturbances has also increased dramatically during this period. Aside from stress and anxiety, two other factors are likely to contribute to increased sleep disturbances during this crisis. First, alterations of our daily routines such as arising at a specific time, showing up at work, eating, exercising, and engaging in social and leisure activities at relatively fixed times are all important timekeepers for our sleep-wake cycles to remain synchronized with the day (light) and night (dark) cycles. Alterations of these timekeepers, combined with reduced daylight exposure, also essential to keep our biological clock synchronized, are likely to disrupt sleep and circadian rhythms. Sleep plays a fundamental role for mental and physical health, and adequate sleep duration and quality are essential for coping with major life events such as the COVID-19 pandemic. Public health education is warranted to keep the population well informed about the importance of sleep and healthy sleep practices in order to cope with the pandemic and prevent or minimize long-term adverse outcomes.
\end{abstract}

\section{Résumé}

Cet article discute de l'importance du sommeil dans un contexte de santé publique, particulièrement en période de crise sanitaire comme celle de la COVID-19, et offre quelques recommandations pratiques et appuyées de données probantes pour gérer les difficultés de sommeil durant cette pandémie. La COVID-19 et l'isolement imposé pendant la pandémie ont produit stress, anxiété et inquiétudes en lien avec la santé et la peur d'être infecté du virus, la perte d'emploi et problèmes financiers, et l'incertitude quant au futur. L'incidence des difficultés de sommeil a également augmenté de manière exponentielle durant cette crise. Outre le stress et l'anxiété causés par la pandémie, au moins deux autres facteurs contribuent à exacerber les problèmes de sommeil. Premièrement, plusieurs routines quotidiennes ont été altérées, notamment celles de se lever à la même heure chaque matin, de se présenter au travail, de manger, s'entraîner, avoir des contacts sociaux et pratiquer des loisirs à des heures relativement fixes; ces activités représentent des marqueurs de temps qui synchronisent nos cycles de veille-sommeil avec les cycles des jours et des nuits. La perte de ces repères, combinée à une réduction de l'exposition à la lumière du jour, essentiel à la synchronisation de l'horloge biologique, contribuent à perturber le sommeil et les rythmes circadiens. Le sommeil joue un rôle fondamental pour la santé mentale et physique; une durée et une qualité adéquate de sommeil permettent de développer une meilleure résilience afin de composer avec des événements de vie majeurs comme la COVID-19. L'éducation grand public est donc nécessaire pour sensibiliser la population à l'importance du sommeil et aux bonnes pratiques d'hygiène du sommeil et ainsi minimiser les conséquences à long terme de la pandémie sur la santé mentale et physique.

Charles M. Morin

cmorin@psy.ulaval.ca

1 Université Laval, 2325, rue des Bibliothèques, Québec, QC G1V 0A6, Canada

2 Centre d'étude des troubles du sommeil, Centre de recherche CERVO, Institut universitaire en santé mentale de Québec, Université Laval, 2325, rue des Bibliothèques, Québec, QC G1V 0A6, Canada
3 Université de Montréal, Montreal, QC, Canada

4 Centre d'étude avancée en médecine du Sommeil, Hôpital du Sacré-Cœur de Montréal, Université de Montréal, Montreal, QC, Canada

5 Clinique du sommeil, Hôpital-Rivières-des-Prairies, Montréal, QC, Canada 
Keywords Pandemic $\cdot$ COVID-19 $\cdot$ Public health $\cdot$ Sleep $\cdot$ Insomnia $\cdot$ Psychological symptoms

Mots-clés Pandémie $\cdot$ COVID-19 $\cdot$ santé publique $\cdot$ sommeil $\cdot$ insomnie $\cdot$ symptômes psychologiques

The COVID-19 pandemic has produced significant stress, anxiety, and worries about health, employment, and financial hardship. This unprecedented crisis has also affected sleep, both in healthcare workers and in the general population, at a time when healthy sleep is critical to build resilience to cope with the casualties of this pandemic. This commentary aims to highlight the critical role of sleep as a public health issue, particularly during a stressful life period such as COVID-19, and provide evidence-based practical guidelines to manage sleep disturbances during this crisis.

How prevalent are sleep problems during this pandemic? Surveys of healthcare workers since the rise of COVID-19 have shown very high rates of insomnia (34-36\%), as well as anxiety (45\%) and depressive symptoms (50\%), and those symptoms are especially prominent among frontline workers directly involved with patients diagnosed or at risk for COVID-19 (Lai et al. 2020; Zhang et al. 2020). Data from the general population also indicate that insomnia, sleep loss, and poor sleep quality are widespread complaints (Cellini et al. 2020), with rates similar to those associated with other major crises involving, for example, natural disasters such as earthquakes, floods, or wildfires (Belleville et al. 2019). Not surprisingly, individuals with more severe anxiety and depressive symptoms also report more sleep disturbances during COVID-19. Conversely, those with a stronger social support network and a sense of belonging report less psychological symptoms and better sleep quality (Xiao et al. 2020).

Why is sleep more disrupted during COVID-19? Any stressful life event, whether related to one's personal life or caused by natural disasters that threaten one's psychological or physical well-being, is likely to precipitate sleep disturbances, and more so among individuals with higher vulnerability. Of course, healthcare workers on the front lines are likely to experience significant stress due to the pressure to organize or provide care to patients, the fear of being infected, and facing death repeatedly, all of which can also disturb sleep when they return home.

With the COVID-19 pandemic, at least two factors beyond stress are also involved: the effects of confinement and atypical work schedules. Sleep-wake schedules are regulated by homeostatic pressure (duration of wakefulness) and the circadian timing system, the latter being controlled by daylight exposure and several social and environmental timekeepers. Those timekeepers include daily routines such as arising at a specific time with an alarm clock, showing up at work at a fixed time, eating, exercising, and engaging in social and leisure activities at relatively fixed times throughout the day and evening. Under confinement conditions, several of those time cues are altered since there are fewer constraints to perform these activities at fixed times. Furthermore, as daylight exposure is the primary factor regulating the circadian timing system, it is crucial to get some daylight exposure in order to maintain a good signal from the circadian timing system, since time spent outdoors is reduced while in confinement. Research investigating sleep and circadian rhythms under temporal isolation in which participants are isolated from the outside world for several consecutive days (they can sleep and eat at their leisure and use artificial light as needed, but no contact with the outside world) has shown that participants' sleep schedules quickly become desynchronized with the outside world (Revell and Eastman 2005). The atypical work schedules of many health workers and security agents doing shifts at different times of day are an important risk factor for sleep disturbances and sleep loss, and such problems can be further exacerbated when those workers return home with childcare and family responsibilities.

\section{Why should we pay attention to sleep during this pandemic?} Healthy sleep - that is, adequate sleep duration, quality, and timing - is one of the three pillars of sustainable health, the other two being diet and exercise. Sleep plays a fundamental role for both mental and physical health. For instance, sleep is very much involved in emotion regulation (Goldstein and Walker 2014) and in immune functions (Irwin 2019). A single night of sleep deprivation can produce significant mood disturbances and lower immune defenses. Chronic insomnia and prolonged sleep loss increase risks of long-term adverse consequences for mental (depression, substance use), physical (hypertension, diabetes), and occupational health (disability) (Morin et al. 2015). We also know that insomnia and nightmares triggered by stressful life events can outlast the crisis over a long period (Lavie 2001). Given these well-established associations, one can safely propose that those individuals who develop significant sleep disturbances during COVID19 may be at greater risk for long-term negative health outcomes. Thus, protecting sleep during this pandemic is particularly important to build resilience and cope more effectively with the social confinement, distress, and uncertainty produced by this pandemic.

How to manage sleep disturbances during COVID-19? Several generic strategies can help prevent or minimize sleep 
problems during this pandemic (see Box 1 and list of resources at the end of this paper). Public sleep health education should be the first priority to provide broad-based information about sleep health (e.g., the importance of maintaining regular sleep schedules, staying away from electronics in the bedroom, obtaining a daily dose of daylight exposure) even during a prolonged period of confinement. For those with persistent insomnia, professional help may be required. Evidence-based treatment options for the clinical management of insomnia include hypnotic medications and cognitive behavioural therapy (Qaseem et al. 2016). Whereas medications may provide rapid relief of insomnia symptoms and may be indicated for acute insomnia, evidence-based systematic reviews, as well as clinical practice guidelines, have all come to the same conclusion that cognitive behavioural therapy should be the first-line treatment for chronic insomnia. Most of these behavioural methods can be adapted to the needs of different individuals during this pandemic (Altena et al. 2020). They can also be made more widely accessible through web-based and telehealth platforms.

Box 1 Strategies to manage sleep disturbances during the COVID-19 pandemic

- Make sleep a priority and reserve at least 7-8 h per night for sleep.

- Keep a regular schedule for sleep, meals, work, and social contacts. These activities are important time cues that help maintain entrainment of one's biological clock.

- Get as much daylight exposure as possible (turn on the lights, open the curtains, go outside if possible) to regulate sleep-wake and circadian rhythms.

- Avoid using electronics (cellular, tablets) in the bed or bedroom or near bedtime.

- Allow at least $1 \mathrm{~h}$ to unwind before bedtime.

- If sleep does not come within 15-20 min, go to another room and engage in quiet activities (reading), and return to bed only when sleep is imminent.

- Reserve the bed and bedroom for sleep and sex only. This is not the place to worry, problem-solve, or plan the next day.

- Get up at the same time every morning, regardless of the amount of sleep. While it may be tempting to sleep in, particularly when there is no obligation to be at work, it is best to arise at the same time to keep a regular sleepwake schedule.

- Although it is better to avoid napping for someone with insomnia, napping is beneficial for sleep-deprived people. Older adults, without sleep problems, may also benefit from a short catnap (15-20 min) around mid-day.

- Keep in mind that short bouts of insomnia is a normal reaction to stressful life events, but when sleep difficulties occur several nights per week, take action and seek professional help to prevent acute insomnia from turning into chronic insomnia.

\section{Conclusion}

Healthy sleep plays a critical role for coping physically and psychologically with major life events such as this COVID19 pandemic. Public health education is essential to keep the general population well informed about the importance of sleep and healthy sleep practices to prevent or minimize long-term adverse outcomes. Evidence-based short-term and long-term interventions are also available, as well as online support strategies.

\section{For more information}

www.sleeponitcanada.ca

www.dormezladessuscanada.ca

https://css-scs.ca/resources/links

https://www.sleepfoundation.org/

Acknowledgements The Canadian Sleep and Circadian Network is an initiative funded by the Canadian Institutes of Health Research.

\section{Compliance with ethical standards}

Conflict of interest Dr. Morin has received research support from Idorsia and Canopy Growth and honorarium for consulting and lecturing from Merck, Eisai, Sunovion, Weight Watchers, and Pear Therapeutics. Dr. Carrier has received research support from Canopy Growth, RANA, Eisai, and Philips Respironics. Dr. Godbout and Dr. Bastien have no conflict to disclose.

\section{References}

Altena, E., Baglioni, C., Espie, C. A., Ellis, J., Gavriloff, D., Holzinger, B., Schlarb, A., Frase, L., Jernelöv, S., \& Riemann, D. (2020). Dealing with sleep problems during home confinement due to the COVID-19 outbreak: practical recommendations from a task force of the European CBT-I Academy. Journal of Sleep Research. https://doi.org/10.1111/jsr.13052 [Epub ahead of print].

Belleville G, Ouellet MC, Morin CM. Post-traumatic stress among evacuees from the 2016 Fort McMurray wildfires: exploration of psychological and sleep symptoms three months after the evacuation. International Journal of Environmental Research and Public Health. 2019;16(9). pii: E1604. doi: 10.3390/ijerph16091604.

Cellini, N., Canale, N., Mioni, G., \& Costa, S. (2020). Changes in sleep pattern, sense of time, and digital media use during COVID-19 lockdown in Italy. Journal of Sleep Research (preprint).

Goldstein, A. N., \& Walker, M. P. (2014). The role of sleep in emotional brain function. Annual Review of Clinical Psychology, 10, 679-708. https://doi.org/10.1146/annurev-clinpsy-032813-153716 Epub 2014 Jan 31. 
Irwin, M. R. (2019 Nov). Sleep and inflammation: partners in sickness and in health. Nature Reviews. Immunology, 19(11), 702-715. https://doi.org/10.1038/s41577-019-0190-z.

Lai, J., Simeng, M., Wang, Y., et al. (2020). Factors associated with mental health outcomes among health care workers exposed to coronavirus disease 2019. JAMA Network Open, 3(3), e203976.

Lavie, P. (2001). Sleep disturbances in the wake of traumatic events. NEJM, 345(25), 1825-1832.

Morin, C. M., Drake, C. L., Harvey, A. G., Krystal, A. D., Manber, R., Riemann, D., \& Spiegelhalder, K. (2015). Insomnia disorder. Nature Reviews. Disease Primers, 1, 15026. https://doi.org/10. 1038/nrdp.2015.26.

Qaseem, A., Kansagara, D., Forciea, M. A., Cooke, M., \& Denberg, T. D. (2016 Jul 19). Clinical Guidelines Committee of the American College of Physicians. Management of chronic insomnia disorder in adults: a clinical practice guideline from the American College of
Physicians. Annals of Internal Medicine, 165(2), 125-133. https:// doi.org/10.7326/M15-2175.

Revell, V. L., \& Eastman, C. I. (2005). How to trick Mother Nature into letting you fly around or stay up all night. Journal of Biological Rhythms, 20, 353-365.

Xiao, H., Zhang, Y., Kong, D., Li, S., \& Yang, N. (2020). Social capital and sleep quality in individuals who self-isolated for 14 days during the coronavirus disease 2019 (COVID-19) outbreak in January 2020 in China. Medical Science Monitor, 26, E923921.

Zhang, C., Yan, L., Liu, S., et al. (2020). Survey of insomnia and related social psychological factors among medical staffs involved with the 2019 novel coronavirus disease outbreak. Frontiers in Psychiatry.

Publisher's note Springer Nature remains neutral with regard to jurisdictional claims in published maps and institutional affiliations. 